\title{
The State of Academic Stress in the Higher Institutions of Ghana: The Way Forward
}

\author{
Dickson Adom ${ }^{1,2, *}$, Harry Barton Essel ${ }^{1}$, Joshua Chukwuere ${ }^{3}$ \\ ${ }^{1}$ Department of Educational Innovations in Science and Technology, Kwame Nkrumah University of Science and Technology, \\ University Post Office, Ghana \\ ${ }^{2}$ School of Economic Sciences, North-West University, South Africa \\ ${ }^{3}$ Department of Information Systems, North-West University, South Africa
}

Received June 11, 2019; Revised January 4, 2020; Accepted January 13, 2020

Copyright $\mathrm{C} 2020$ by authors, all rights reserved. Authors agree that this article remains permanently open access under the terms of the Creative Commons Attribution License 4.0 International License

\begin{abstract}
Stress resulting from academic work among lecturers and students in Ghanaian higher institutions greatly affects their health and academic output. The study aimed at identifying the sources and causes of academic stress in the higher institutions in Ghana while suggesting effective stress coping mechanisms. The study was driven in the convergent parallel mixed method research with questionnaire administration, private interviews and focus group discussion as data collection tools. A total of 478 sampled respondents in three higher institutions in Ghana were involved in the study. This included 74 lecturers and 404 students in three higher institutions in Ghana. The findings of the study revealed that lack of planning of work schedule, unnecessary delays of work while striving to meet deadlines or procrastination, poor eating, sleeping and exercise habits as well as unrealistic academic goals were the main causes of academic stress. The study contends that the setting of healthy academic goals, good planning and schedule of academic work, giving room for exercise and relaxation at regularly planned intervals, meticulously following healthy eating and sleeping habits as well as Africultural coping mechanisms were the effective management strategies of academic stress. The study tasks the Ministry of Education and the regulatory bodies of higher institutions in Ghana to ensure the setting of guidance and counseling units as well as task welfare committees to periodically organize workshops and seminars to sensitize the members of the higher institutions on the dangers of academic stress and effective approaches in curtailing them.
\end{abstract}

Keywords Academic Stress, Stress Management, Stress, Teaching and Learning, Higher Education

\section{Introduction}

Stress is an inevitable body condition or experience that entangles every human being irrespective of their unique demographic characteristics [1,2] as each tries to adjust to the ever-changing human society [3]. The word 'stress' is etymologically derived from the Latin word 'Stringere' which means to draw tight and it was used in the early 1700s to describe pain, hardship or affliction [1]. Early stress theorists such as Canon [4], Selye [5] and Mason [6] theorized stress on the physiological basis and defined it as the pressure an individual faces from the environment strain within himself or herself. However, today, stress is considered as the interaction between a situation and an individual [7]. It is seen as the perception of discrepancy between environmental demands (stressors) and an individual's capacities to cope with these stressors [8]. Stress is described as the response of mental action through hormonal signaling with the perception of danger setting off an automatic response system known as the fight and flight response [9]. Stress always presents itself when the internal and external pressures exceed the individual's resources to cope with the situation [10].

Many researchers posit that stress is not an entirely disturbing phenomenon [10, 2]. Wani, Nagar, and Buhroo [11] aver that stress is generally accepted by stress theorists as having two opposite effects which are positive stress (eustress) and negative stress (distress). Saqib [9] and Yikealo, Tareke, and Karvinen [12] contend that from an adaptive point of view, mild stress can be very beneficial for both faculty and students as it serves as a motivator for hardwork and eventual productivity. Avoiding stress completely is seen as leading to a very boring life [13]. However, high and uncontrolled stress can have dire mental, psychological and physical consequences [14-16]. This concurs with the view of Cooper and Quick [17] who described stress as the spice of life and the kiss of death. 
Stress has become an important and urgent topic for academic research $[18,19]$ because academic stress has been an age-long canker in higher institutions [20] due to the high academic demands and professional expectations from students and faculty respectively [21, 22]. The pursuance and administration of higher education are stressful to students who are mandated to adapt to the new educational and social environments [1] and faculty who are expected to undertake very intensive faculty work [23, 24]. The existence of stress is a result of the presence of stressors [25], events or stimulus that propels a person to experience stress. The two most disturbing stressors in higher institution environments are academic-related stressors and institutional stressors [26].

Stankovska, Dimitrovski, Angelkoska, Ibraimi, and Uka [27] conceptualizes academic stress as a person's interaction with environmental stressors, his or her cognitive appraisal and coping mechanism of the academic-related stressors as well as a psychological or physiological response to the stressors. However, academic stress cannot be limited to only academic-related stressors [28]. All kinds of stressors (intrapersonal/self stressors, interpersonal/social stressors, time/balance stressors, institutional stressors, financial stressors, and others) that impede academic output of students and professional expectations of faculty, thereby causing unpleasant psychological and physical situations qualifies as academic stress [11]. Aam, Sara, and Adamu [29] concur that all forms of performance-related anxiety in academic institutions of learning constitute academic stress. Academic stress is a career stopper [30] as it stifles the professional growth of faculty. The position of the researchers is that every kind of stress that significantly inhibits the psychological wellbeing of students [2] and faculty, thereby negatively affecting their academic and professional outputs exemplifies the term academic stress.

The common stressors that impede academic and professional performance of students and faculty identified by researchers include academic and coursework overloads [27, 31]; financial difficulties [16]; poor eating and sleeping habits [32]; health problems [23]; college environmental situation [33]; poor time and resource management [2], domestic responsibilities [14], examination [34], social comparison and competition [1], lack of academic guidance [35], high expectations from family and teachers [12], pressure to secure a 'respectable' job from excellent academic performance [36], thoughts of failure [37], preparation for oral presentations [38] and lack of friendship and family support [39]. Stress negatively affects an individual's psychology, physiology, and sociology [40]; drastically reduce his or her learning and memory [41]; preempt suicidal ideation [42]; decreases one's productivity [16]; depression and cognitive worry [43]; lack of energy and sleeping disorders such as sleep-wake systems [1]; behavioral symptoms such as loss of appetite, increased consumption of alcohol, tobacco, and food [36]; diminished students' motivation and enthusiasm [44]; reducing the cumbersome academic plan and procedures while teaching stress coping mechanisms through advocacy programmes [2]; risk factor for psychopathology [10] and low self-esteem [45].

Many ways of managing academic stress have been suggested by researchers. Some of these include the university administration offering avenues for student consultation with psychologists in addressing the negative effects of academic stress [46]; encouraging students and fostering good student-teacher relationship [11]; reading books, listening to music and watching movies [12]; social support systems [23, 36]; learning to set limits [10]; assigning academic mentors and counsellors for students [29]; implementation of mindfulness practices in the classrooms [34]; music therapy [23]; psychotherapy [15]; realistic assessment of students [18]; getting enough sleep and having regular exercises [3]; engagement in physical and extracurricular relaxing activities [21]; university management team creating a conducive learning environment with suitable teaching and learning methods [1].

Many of the studies on academic stress in higher institutions globally have generally focused on students with few assessments of the stress on faculty $[47,42,27,12$, 10]. Also, many of the studies on academic stress are limited to particular year levels [48, 49] and single programmes of studies such as business students [26], pharmacy students [47], medical students [22, 50]. From the Ghanaian perspective, Duncan-Williams [36] investigated the relationship between the academic stress faced by Senior High school remedial students in the Greater Accra Region of Ghana and their psychological well-being. She utilized the Student-Life Stress Inventory (SLSI), Depression Anxiety Stress Scale (DASS- 42), the Africultural Coping Systems Inventory (ACSI), Multidimensional Scale of Perceived Social Support (MSPSS) and the Academic Self-Efficacy Scale. Results from her analysis showed a positive relationship between academic stress and the psychological well-being of the remedial students with the Hierarchical Multiple Regression analyses indicating that social support, africultural coping, gender, and socio-economic status did not moderate the relationship between stress and psychological well-being though she noticed gender differences in the psychological well-being of the students. Azila-Gbettor et al. [26] assessed stress sources and their effects on the academic performance of Business Students in Ho Polytechnic, Ghana using a cross-sectional research design. They found out that Total Environmental/ Campus/ Administrative/ transition Stressors and Total Academic Stressors were the dominant stressors that affected academic performance among the students. There is still a significant dearth of studies that focus on assessing academic stress faced by students generally and faculty in tertiary institutions of Ghana. If Ghana will be able to 
achieve the Continental Education Strategy for Africa (16-25) [51] strategic objective nine which calls for the revitalization and expansion of tertiary education, research, and innovation to address the continental challenges and promote global competitiveness, there is the need to address the academic stress that hinders academic growth. Previous studies on academic stress in the Ghanaian tertiary institutions have been limited to one academic institution, students studying the same programme and in the same year as well as using only quantitative data set [52, 36, 26]. Essel and Owusu [16] suggested that for a more in-depth study on academic stress in higher institutions of learning, future researchers should approach the topic by using both quantitative and qualitative sets of data as they would yield a richer and more comprehensive understanding of the subject. This study utilizes the convergent parallel mixed method approach in soliciting for both qualitative and quantitative sets of data on academic stress. Dhanalakshmi and Murty [53] suggested the assessment of the academic stress of students studying various programmes. They argued that academic stress studies in higher institutions should not be limited to a particular programme of study. Based on this backdrop, this study assesses the academic stress of Ghanaian students in various faculties, academic levels, and programmes of study. More significantly, the study is the maiden in the Ghanaian context for assessing the academic stressors and coping mechanisms for faculty vis-a-vis the recent academic stressor to publish more research findings fuelled by the famous 'publish or perish' slogan in tertiary institutions globally. The study hinges on three research questions: 1. What are the sources of academic stressors among faculty and students in the selected higher institutions of Ghana? 2. What are the causative agents of the identified academic stressors among faculty and students in the selected higher institutions of Ghana? 3. What are the effective ways of managing the academic stress identified among faculty and students in the selected higher institutions of Ghana?

\section{Materials and Methods}

The study adopted the convergent parallel mixed methods design (Figure 1). This was because the researchers wanted to have a holistic comprehension [54] of academic stress in the selected higher institutions in Ghana by obtaining both qualitative and quantitative data sets. Further, the researchers wanted to get mutual confirmation of the findings to bolster the validity of results from the study [55].

The descriptive study was utilized to systematically document the current state [56] of academic stress in the selected higher institutions in Ghana among students and faculty. The FGDs were video recorded to assist in easy association of the voices to the right people and ultimately to ease coding and final analysis [57]. On the other hand, the private interviews were audio-recorded so that the researchers could play them at different time to fully understand the import of the views of respondents. The remaining 386 respondents whose responses were recorded via the questionnaire administered were selected conveniently and then randomly in various departments in the selected higher institutions (Table 1).

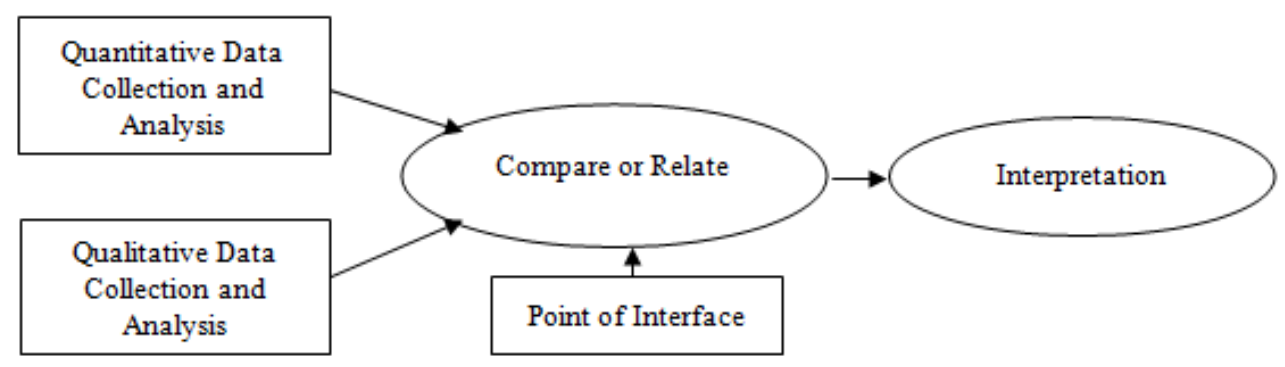

Figure 1. Convergent Parallel Mixed Methods Design (54)

Table 1. Sampling Breakdown

\begin{tabular}{|c|c|c|c|c|c|c|}
\hline $\begin{array}{c}\text { Tertiary } \\
\text { Institution }\end{array}$ & Lecturers & $\begin{array}{c}\text { Number of } \\
\text { lecturers } \\
\text { interviewed } \\
\text { privately }\end{array}$ & $\begin{array}{c}\text { Number of } \\
\text { lecturers } \\
\text { Questionnaire were } \\
\text { administered }\end{array}$ & Students & $\begin{array}{c}\text { Number of students } \\
\text { who were } \\
\text { administered with a } \\
\text { questionnaire }\end{array}$ & $\begin{array}{c}\text { Number of } \\
\text { students who } \\
\text { were engaged } \\
\text { in the FGDs }\end{array}$ \\
\hline Ghana 1 & 25 & 12 & 13 & 134 & 114 & 20 \\
\hline Ghana 2 & 25 & 12 & 13 & 134 & 114 & 20 \\
\hline Ghana 3 & 24 & 8 & 16 & 136 & 116 & 20 \\
\hline TOTAL & $\mathbf{7 4}$ & 32 & 42 & $\mathbf{4 0 4}$ & 344 & 60 \\
\hline GRAND TOTAL & & \multicolumn{2}{|c|}{$\mathbf{4 7 8}$} & \\
\hline
\end{tabular}


The quantitative data were collected by administering both electronic (Google form) and hard copies of the developed questionnaire. The electronic questionnaires were administered randomly to students and lecturers from different faculties and at different academic levels and professional qualifications. The hard copies were administered conveniently in the various faculties aimed at targeting participants who had challenges with sharing their views electronically and as such preferred to share their views via writing on the printed copies. The respondents were instructed to complete the questionnaire by giving a response to every item on the questionnaire. Keeping in view the objectives as well as the design of the study, measures of central tendency and dispersion, coefficient of correlation and T-test were used for the analysis of the quantitative data set. Descriptive statistics, specifically, Mean and Standard Deviation were employed in the study. Pearson's product-moment Correlation Coefficient was computed to analyze the relationships between constructs. Inferential statistics such as an independent sample $\mathrm{T}$-test was used to find the significance of the differences between the means with an alpha or significant value of $0.05(5 \%)$ and confident interval (CI) of $95 \%$.

On the other hand, the qualitative data set from the personal interviews and focus group discussion were analyzed using the data analysis spiral. The qualitative data generated was initially coded; relationships in the data were identified; emergent themes or patterns were created and generalizations from the emergent themes were made [58].

\section{Results}

\subsection{Emergent Themes from the Qualitative Data}

3.1.1. Sources of Academic Stressors among Faculty and Students in Ghanaian Higher Institutions

3.1.1.1. Excessive Academic Demands on Faculty and Students in Ghanaian Higher Institutions (Publication Demands, Examination, Oral Presentations, Student Assessment, Final Year Project Work/Thesis)

The students mentioned that excessive academic stress is a result of the intensive academic demands expected from students and faculty. In one of the group focus sessions, the students summarized the pressure imposed on them to perform diverse academic responsibilities as:

'We have turned into thinking machines and stress is inevitable sometimes' (ST-FGD-5, Personal Communication, 10/3/2019).

In terms of the academic stressors, both the faculty and student participants cited many of the demands of academic work. In terms of the order of academic work that stressed the lecturers were student assessments, publication demands, and organizing students' field trips. In terms of research publication demand, one lecturer who is requiring a certain number of publications for his next promotion mentioned:

I think the recent 'publish or perish' virus is causing the most stress among the teaching staff in tertiary institutions. Amid the large classes of students and numerous courses to teach, the lack of grants and the not forthcoming research allowance, undertaking breathtaking research is very difficult now. This accounts for the low standard studies published in predatory journals among some teaching staff in tertiary institutions (LG3, Personal Communication, 12/3/2019).

On the part of the students, examinations, presentations in class, thesis preparation and excessive demands from teachers and parents to perform well triggered academic stress. The thought of failing an examination or being unable to finish their programmes of study due to their inability to write their final year thesis causes the most stress as it was noticed in the focus group discussions. Three postgraduate students who are financially supported by their family members shared similar thoughts:

We must, by all means, submit our theses to be able to graduate and the demands of the thesis write-up, unsupportive supervisors and our work demands make it difficult for us to carry out our research on time (ST-FGD-4, Personal Communication, 15/3/2019).

They added that the thought of disappointing their supportive families by being unable to finish their programmes of study is a great stressor to them.

\subsubsection{Psychosocial Sources of Academic Stressors among Teaching Staff and Students in Ghanaian Higher Institutions}

The researchers noticed that other psychosocial factors such as parenting, child care, breakdown in romantic relationships and financial problems were cited by some of the lecturers and students as the sources of their academic stress. The female postgraduate students who were married and had children said that childcare had a heavy toll on their academic performance. Many of the students in the focus group discussion, especially the undergraduate students indicated that they had financial challenges with paying their tuition fees, buying pamphlets and undertaking assignments that required the purchase of items or performance of experiments. Also, breakdown in romantic relationships was cited by the teaching staff and students as the most psychosocial stressor that negatively impacted on their academic and professional demands. Some of the lecturers mentioned that quarrels and unstable peace with their spouses stressed them and thereby impacted negatively on their professional output. Likewise, the students disclosed that their colleagues who have been jilted by their partners in romantic relationships registered 
poor academic performances.

\subsubsection{Causative Agents of the Academic Stressors among Faculty and Students in Ghanaian Higher Institutions}

The failure of students and faculty in skillfully managing their time for the excessive academic workload resulted in academic stress. Many of them resulted in procrastination even when the deadlines for projects on their timetables were due for execution. They are then entangled in the web of academic stress when they are required to submit student assessments and technical reports (on the part of lecturers), oral presentations, written assignments, practical projects and final year thesis (on the part of students).

\subsubsection{Effective Ways of Managing the Academic Stress} Identified among Faculty and Students in Higher Institutions of Ghana

\subsubsection{Good Management of Time and Organizational Skills}

Academic stress is inevitable in higher institutions so the best option according to the respondents is to manage and organize the time resource and academic demands. One teaching staff who also held this popular view said:

Management is a keyword here. Stress is inevitable. It is integral to existence itself. I guess you are talking about keeping stress under reasonable levels. To achieve anything you need to stretch and stress up yourself a bit but then find a way of unwinding periodically (LG1, Personal Communication, 3/4/2019).

Similar views were shared by the other lecturers and students that proper planning and having a scale of preference for the academic and/or professional demands would help in avoiding stress.

\subsubsection{Regular Exercise}

Exercising constantly was another popular view held by many of the respondents as an antidote for academic stress. One lecturer said that engaging in bodily exercise should be done regularly. Other lecturers suggested engagement in a sport such as playing football every weekend as a source of exercise to ease academic stress. Taking long walks every morning as a form of exercise was also mentioned as a stress buster. In one of the student focus group discussions, the students disclosed the health benefits of exercise. Three biochemistry students unanimously opined that:

'Exercise should be key as it produces endorphin and improves cognitive function' (ST-FGD-5, Personal Communication, 22/3/2019).

\subsubsection{Music Therapy}

The students admitted listening to soulful music as 'a wonderful stress buster' in one focus group session. A lecturer said he played musical instruments as a stress reliever before resuming his busy academic workload.

\subsubsection{Mindful Meditation and Interaction with Nature}

Four lecturers interviewed indicated that meditation has been a tool for relieving their academic stress. One of them advised:

'Meditate if you can, imageless, wordless and thoughtless' (LG3, Personal Communication, 18/3/2019).

Some of the students and lecturers mentioned that drawing close to nature through sightseeing or installation of a home-made aquarium reduced their academic stress. They disclosed that the watching of the animals engaging in their daily activities helped in reducing academic stress.

\subsubsection{Having a Strong Social Support}

Maintaining supportive social relations such as family and friends was seen as a stress reliever by many of the respondents. The students admitted that having a supportive family and friends to lean on in times of distress speeds up the recovery processes. Thus, to reduce stress, a faculty member admonished:

'Honor your relationships. Catch up with your family and friends. Be present with them and listen to them. It reduces stress' (LG3, Personal Communication, 19/3/2019).

Other lecturers supported this view and said they engaged in domestic activities with their families to release the stress from academic work. The students whose family members were distant disclosed that they found solace, peace, and happiness anytime they looked at their family pictures. They added that it assured them that they were not alone in their academics and that they had the unflinching support of their family and friends. Psychologically, it freed them from academic stress, they admitted.

\subsubsection{Make Time for Relaxation}

Due to the often busy schedules of both faculty and students, many of them suggested taking time off from academic work to relax as a coping mechanism for academic stress. One professor suggested that:

'Schedule specific periods to relax, exercise or just disconnect is a good way to manage academic stress' (LG2, Personal Communication, 21/3/2019).

Taking breaks from academic work, according to many of the teaching staff, was crucial in academic stress management. The students suggested going for a vacation for a period to ease academic stress and rejuvenate the mind.

\subsubsection{Setting Healthy and Realistic Academic Goals}

One causative agent of stress mentioned during the interviews was being overly ambitious in one's academic expectations or professional achievements. However, those ambitious goals, according to the respondents, must be realistic. One junior lecturer advised, 'try to have limitations in dreaming' (LG2, Personal Communication, 
14/3/2019). The students also suggested that striving to achieve everything in perfection could trigger academic stress. They warned, 'Resist perfectionism' (ST-FGD-5, Personal Communication, 2/4/2019). They added that complex tasks must be broken into simple tasks planned at regular intervals to minimize academic stress.

\subsubsection{Healthy Life, Nutrition and Sleeping Habits}

Under stressful moments, many academics forfeit good eating and sleeping habits which rather increases their levels of academic stress. Thus, it was suggested in the interviews that taking in more fluids, especially water, eating healthy and nutritious meals while following a healthy sleep pattern would energize the body to overcome academic stress. Also, one lecturer advised both lecturers and students to have 'Routine health behaviors such as self-care, vehicle safety and drug avoidance' (LG1, Personal Communication, 27/3/2019).

\subsubsection{Using Africultural Coping Mechanisms}

The researchers noticed that a significant number of respondents interviewed resorted to Africultural coping mechanisms such as prayers, reading religious books and attending church programs as a means of managing academic stress. Some of the students in the focus group discussion said that they attended prayer sessions anytime examinations were due to release their pent up academic stress. They said:

'Attending a church program or prayer sessions before an examination helps me to calm down' (ST-FGD-1, Personal Communication, 10/3/2019).

Other students said they were calmed down psychologically whenever they said a word of prayer or read their favorite Bible scripture under very stressful academic conditions.

\subsection{Findings from the Quantitative Data Set}

\subsubsection{Sources of Academic Stressors among Faculty and} Students in Ghanaian Higher Institutions

The overall 19-item scale for the sources of academic stressors (Table 2) among faculty and students in Ghanaian higher institutions demonstrated a good internal consistency as measured by Cronbach's alpha $(\alpha=.87)$. The individual factors showed a fair internal consistency of average alpha .86. The three most important sources of academic stressors identified were financial and money problems $(M=3.58)$, academic/coursework demands $(M=3.56)$ and housing/accommodation problems $(M=3.40)$.

\subsubsection{Causative Agents of the Identified Academic} Stressors among Faculty and Students in Ghanaian Higher Institutions

The general 15-item scale for the causative agents of the identified academic stressors (Table 3) among faculty and students in Ghanaian higher institutions showed a high internal consistency as measured by Cronbach's alpha ( $\alpha$ $=.85$ ). The individual elements showed a very good internal consistency of average alpha .83 . The three most important causes of academic stressors identified were procrastination $(M=3.72)$, lack of planning of work schedule $(M=3.65)$ and keeping up with academic activities and tasks $(M=3.54)$.

Table 2. Sources of Academic Stressors

\begin{tabular}{|c|c|c|c|}
\hline & Mean & Std. Deviation & $\mathrm{N}$ \\
\hline University/College & 2.27 & .977 & 386 \\
\hline Academic/Coursework Demands & 3.56 & 1.128 & 386 \\
\hline Finances and Money Problems & 3.58 & 1.190 & 386 \\
\hline Housing/accommodation Problems & 3.40 & 1.064 & 386 \\
\hline Transport & 2.21 & .930 & 386 \\
\hline Change in Living Conditions & 1.39 & .885 & 386 \\
\hline Change in Sleeping Habits & 2.98 & .664 & 386 \\
\hline Change in eating Habits & 2.97 & .864 & 386 \\
\hline Mental Health Problems & 1.68 & .872 & 386 \\
\hline Physical Health Problems & 2.16 & .894 & 386 \\
\hline Parenting issues & 1.85 & .848 & 386 \\
\hline Childcare & 1.67 & .764 & 386 \\
\hline Family Relationships & 1.90 & .816 & 386 \\
\hline Relationships break-down & 1.94 & .937 & 386 \\
\hline Language/Cultural Issues & 1.90 & .864 & 386 \\
\hline Discrimination & 1.10 & 1.080 & 386 \\
\hline Friendships & 1.89 & .742 & 386 \\
\hline Romantic Relationships & 2.70 & .937 & 386 \\
\hline Parental Expectations & 1.18 & .982 & 386 \\
\hline
\end{tabular}

NB: $n=386$; scale: $0=$ not at all to $4=$ Mostly 
Table 3. Causative Agents of the Identified Academic Stressors

\begin{tabular}{|c|c|c|c|}
\hline & Mean & Std. Deviation & $\mathrm{N}$ \\
\hline Procrastination & 3.72 & 1.175 & 386 \\
\hline Lack of planning of work schedule & 3.65 & 1.135 & 386 \\
\hline Poor Sleeping Habits & 2.14 & .871 & 386 \\
\hline Poor Eating Habits & 2.98 & .805 & 386 \\
\hline Uncensored Academic Ambitions & 3.20 & .862 & 386 \\
\hline Work Expectations & 2.73 & .886 & 386 \\
\hline Financial Rewards & 1.18 & 1.076 & 386 \\
\hline Family discussions and conflicts about the studies & 1.80 & .867 & 386 \\
\hline Making Leisure time and academic work compatible & 2.15 & .871 & 386 \\
\hline Teachers Pressure & 2.18 & 1.107 & 386 \\
\hline Keeping up with Academic Activities and Tasks & 3.54 & 1.939 & 386 \\
\hline Too much responsibility to fulfill & 2.30 & 1.021 & 386 \\
\hline Competitiveness among classmates & 2.21 & 1.094 & 386 \\
\hline Presentations of work in class & 2.30 & 1.027 & 386 \\
\hline
\end{tabular}

NB: $n=386$; scale: $0=$ not at all to $4=$ Mostly

Table 4. Ways of Managing Academic Stress

\begin{tabular}{|c|c|c|c|}
\hline & Mean & Std. Deviation & $\mathrm{N}$ \\
\hline Setting healthy academic goals & 3.44 & 1.410 & 386 \\
\hline Good Planning and schedule of academic work & 3.86 & 1.282 & 386 \\
\hline Giving room for exercise & 3.43 & 1.163 & 386 \\
\hline Relaxation at regularly planned intervals & 3.46 & 1.176 & 386 \\
\hline Meticulously following healthy eating and sleeping habit & 2.81 & 1.237 & 386 \\
\hline Setting up of guidance and counseling units & 2.89 & 1.359 & 386 \\
\hline Africultural Coping Mechanism & 3.75 & 1.280 & 386 \\
\hline
\end{tabular}

NB: $n=386$; scale: $1=$ do not apply to $5=$ used greatly

\subsubsection{Ways of Managing Academic Stress among Faculty and Students in Ghanaian Higher Institutions}

The overall 7-item scale of the ways of managing academic stress among faculty and students in Ghanaian higher institutions (Table 4) showed a fairly high internal consistency as measured by Cronbach's alpha $(\alpha=.87)$. The individual items showed a good internal consistency of the average alpha .86 . The three most important causes of academic stressors identified were good planning and schedule of academic work $(M=3.86)$, the use of africultural coping mechanisms $(M=3.75)$ and setting healthy academic goals $(M=3.44)$.

\subsection{Discussion}

\subsubsection{Research Question 1: The Sources of Academic} Stressors among Faculty and Students in the Higher Institutions of Ghana

The leading sources of academic stress as showed in both the qualitative and quantitative data are academic and course workloads, financial problems, as well as high expectations from family, teachers, and superiors at work.
The pressure imposed on faculty members to constantly publish or risk losing their stay in the universities coupled with the high excellence required of faculty in terms of teaching and student assessment is a major source of stress [27]. This is true especially for lecturers who desperately need these research publications for promotion. In the case of students in the Ghanaian higher institutions, intensive coursework overload is a great source of academic stress as noted by Shkulaku [31] as well as Nandamuri and Gowthami [59]. This may be due to the comprehensive nature of the Ghanaian academic curriculum where students read unimportant courses linked with their chosen programmes of study. Similar findings were noted by Amanya, Nakitende and Ngabirano [60], Bedewy and Gabriel [61] and Zeidner [28] among Ugandan, Egyptian as well as Arab and Jew students respectively. This puts unnecessary examination phobia $[53,34]$ in students as they have to make time to learn all the vast nature of the content of myriads of courses every semester and pass very well due to the high academic expectations from family and teachers [12,23]. This may be one of the causes of the high examination malpractices noted recently in the 
general Ghanaian education system.

Also, financial problem is cited as one of the major stressors among faculty and students. This probably is a result of the poor financial conditions in Ghana and the exorbitant tuition fees [16]. The unbridled domestic financial obligations expected $[14,62]$ from faculty members by their families and friends owing to the wrong perception that they are well paid. Many lecturers have to engage in extra-academic engagements in other institutions to earn extra money to cushion them for these financial obligations. This breeds academic stress that negatively affects their academic and professional outputs and reduces their life expectancy ratios.

\subsubsection{Research Question 2: The Causative Agents of the Identified Academic Stressors among Faculty and Students in the Higher Institutions of Ghana}

Procrastination, as well as poor planning and time management in keeping up with the academic and professional responsibilities of faculty and students, were the main causative agents of the identified academic stressors in both the qualitative and quantitative data sets. Waiting for the last hour in carrying out academic work such as student assessment, presentations, thesis writing, studying for examination and research activities were noted to cause the most academic stress among faculty and students in Ghanaian higher institutions. This is similar to the findings of Azila-Gbettor et al. [26] among the business students in the Ho Technical University in Ghana. Likewise, Bukoye [2] noticed the high procrastination rate among undergraduate students at the IBB University in Lapai in Nigeria. Failure to plan their work schedules and academic course work demands [63] often resulted in high arrears of tasks to be performed by faculty and students in Ghanaian higher institutions. Striving to meet deadlines by performing heavy tasks within a relatively shorter period resulted in high mortality rates among faculty and students [42] as well as low standard academic and professional outputs [11].

\subsubsection{Research Question 3: Effective Ways of Managing the Academic Stress Identified among Faculty and Students in Higher Institutions of Ghana}

Among the seven suggested ways of managing academic stress, good time management, the use of Africultural coping mechanisms and the setting of healthy and realistic academic goals were the main stress management mechanisms suggested in the qualitative and quantitative data sets. Academic stress cannot be ruled out completely from higher institutions [3]. Therefore, the key strategy is to manage academic stress efficiently. This concurs with the view of Lin and Chen [40] who posited that good planning of work and academic schedule will aid both students and faculty in completing their assigned tasks on time and reduce academic stress. Similarly, Ng et al. [23], as well as Bakksh and Sayed [3], noted that effective time management resulted in improved academic grades of students and of course, the professional output of faculty. Thus, this study buttresses the suggestion of Aam et al. [29] that academic counsellors must guide students, especially the fresh entrants toward inculcating in them skills on good time management to assist them to efficiently manage their time for academic/coursework demands. Another important coping mechanism for academic stress noted among the faculty and students in Ghanaian higher institutions was the use of Africultural coping strategies such as maintaining religiosity and spirituality [64]. The findings revealed that the use of prayers, attending religious programs, enjoying the social support of religious brothers and sisters as well as the reading of religious books (Holy Bible and Holy Quran) assisted both faculty and students in managing their pent up academic stress.

Also, the findings of the study indicated that faculty and students need to set realistic academic goals and ambitions so as not to be caught in the web of academic stress. D'chunha and Shah [65] share the same view that students and faculty must learn to set limits in academic targets and ambitions. These set targets must correlate with their academic abilities, interests, performances, and resources available to them. Otherwise, their set of academic ambitions will only be wishful dreams and thinking. This finding maybe because of the high religious climate in Ghana as realized by Adom [66] in his work on the use of the Asante cosmology and belief systems as a catalyst for nature conservation. Similar findings in previous studies on academic stress are in unison with this finding. For instance, Vasquez [62] realized that social support of the members of the church and religious bodies among learners in the Latino community while Tartaro, Luecken, and Gunn [67] also noted that the religiosity and spirituality in terms of prayers lowered blood pressures and eased stress among young adults, some from African-American descents. Yikealo et al. [12] also found out that the reading of the Holy Bible and the Holy Quran among students of the Christian and Islamic religious association in the college of education in the Eritrea Institute of Technology aided them in managing effectively, their academic stress.

\section{Conclusions}

The study was carried out to investigate the sources, causative agents and effective management strategies for academic stress among faculty and students in some Ghanaian higher institutions. The study has shown that academic stress cannot be ruled out completely from the academic life of both faculty and students in academic institutions of learning. The sources of academic stress in Ghanaian higher institutions noted were financial problems, academic and course work demands, high academic and professional expectations from parents, teachers and university management and many others. Procrastination 
and poor time management as well as setting unrealistic academic and professional goals and ambitions were the identified causative agents of the academic stressors. Finally, the effective stress coping mechanisms suggested amongst others by the study were good time management, the use of Africultural coping mechanisms and the setting of healthy and realistic academic goals. These recommendations have been forwarded for policy implementation to assist in managing academic stress among faculty and students in Ghanaian higher institutions:

1. University management through their data analysis units in appropriate departments must conduct a family economic earnings/status survey of new entrants to be able to know students who need financial assistance and make these documents available to student fund awarding institutions and student loan trust funds to assist such students. The modalities for application and payment must be flexible to allow the needy students to be able to apply for such scholarships and loan facilities to be able to address the financial problems that cause academic stress.

2. The welfare associations of higher institutions in Ghana must organize seminars and talk shows to sensitize the general public especially families of university faculty not to impose unnecessary stress on faculty members to perform extraneous and hard-to-reach financial obligations under the wrong perception that they are financially sound.

3. The university management team must organize time management and proper organizational skills workshops and seminars must be organized for both faculty and students by the university management via concerned agencies and experts to sensitize and enlighten them on proactive ways of managing their time to eradicate academic stress.

4. Curriculum developers must incorporate the teaching of stress management strategies as an essential module in the school curriculum. Such a generalized course must be made mandatory but non-scoring for all students in the various higher institutions in Ghana.

5. Courses that are not directly related to programmes of study by students must be taken out of their academic curriculum or made optional/non-scoring by the curriculum planning committees in the higher institutions of Ghana to reduce academic stress in students.

\section{Acknowledgements}

We are very grateful to experts in academic stress and stress management on the Research Gate academic platform where discussions on the conceptualized idea for this research were initiated. Also, the researchers thank the students and lecturers in the Kwame Nkrumah University of Science and Technology, the Sunyani Technical University and the St. Louis College of Education for willingly participating in the study. We appreciate the kind assistance of our research assistants, Ophelia Addai, Samuel Teye Daitey, Samuel Kissi, Michael Amponsah and Paul Sekyere who assisted us with the administering of the questionnaires as well as the organization of the numerous personal interviews and focus group discussions for the study. We sincerely appreciate the travel grant offered by the Association of African Universities (AAU) to the principal investigator, Dr. Dickson Adom, to present the paper at the Conference of Rectors, Vice Chancellors and Presidents of African Universities (COREVIP) 2019. The researchers appreciate the intelligent and great suggestions received from the conference participants. We are thankful to the reviewers for their insightful and very helpful comments that have improved the rigor of the paper.

\section{REFERENCES}

[1] Ramachandiran, M. \& Dhanapal, S. Academic Stress among University Students: A Quantitative Study of Generation Y and Z's Perception. Partanika J. Soc. Sci. \& Hum. 2018, 26(3): 2115-2128

[2] Bukoye, R. O. Academic Stress and Drug Abuse Factors Inhibiting Psychological Well-Being among Undergraduates: Its Counselling Implications. European Scientific Journal, 2017, Vol. 13, No. 8, pp. 60-74

[3] Bakhsh, M. M., \& Sayed, S. A. Sources of Academic Stress: Stress Management among Regular and Executive MBA Students. International Journal of Endorsing Health Science Research, 2015, 3(1), 17-22.

[4] Canon, W. B. The Interrelations of Emotions as Suggested by Recent Physiological Researches. American Journal of Psychology, 1914, 25, 256-282

[5] Selye, H. The Stress Concept: Past, Present, and Future. In: Cooper, C.L. (Ed), Stress research: issues for the eighties. 1965, New York: John Wiley \& Sons, 1-20

[6] Mason, J. W. A Reevaluation of the Concept of 'Non-Specificity' in Stress Theory. Journal of Psychiatric Research, 1971, 8, 323-333.

[7] Michie, S. Causes and Management of Stress at Work. Occupational and Environmental Medicine, 2002, Vol. 59, Issue 1, pp. 67-72

[8] Kaur, A. Academic Stress and Time Management in Adolescents. The Int. Journal of Social Sciences and Humanities Invention, 2016, Vol. 3, Iss. 1, pp. 1790-1792

[9] Saqib, M. Impact of Stress on Students Academic Performance at Secondary School Level at District Vehari. Int. Journal of Learning and Development, 2018, Vol. 8, No. 1, pp. 84-93 
[10] Aafreen, M. M. , Priya, V. V. \& Gayathri, R. Effects of Stress on Academic Performance of Students in Different Streams. Drug Intervention Today, 2018, Vol. 10, Iss. 9, pp. 1776-1780

[11] Wani, S. A., Nagar, D. \& Buhroo, A. A. Impact of Academic Stress on Academic Achievement: A Systsematic Review of Literature. 2nd International Conference on Research Developments in Arts, Social Science and Humanities. Indian Council of Social Science Research (ICSSR), 8th-9th April, 2018. www.conferenceworld.in (Accessed $12 / 2 / 2019$ )

[12] Yikealo, D., Tareke, W. \& Karvinen, I. The Level of Stress among College Students: A Case in the College of Education, Eritrea Institute of Technology. Open Science Journal, 2018, 3(4): 1-18

[13] Veena, N. \& Shastri, S. Stress and Academic Performance. The International Journal of Indian Psychology, 2016, Vol. 3, Iss. 3, pp. 71-82

[14] Jain, G. \& Singhai, M. Academic Stress among Students: A Review of Literature. Prestige e-Journal of Management and Research, 2018, Vol. 4, Issue 2, pp. 58-67

[15] Reddy, K. J., Menon, K. \& Thattil, A. Understanding Academic Stress among Adolescents. Artha-Journal of Social Sciences, 2017, Vol. 16, No. 1, pp. 39-52

[16] Essel, G. \& Owusu, P. Causes of Students' Stress, Its Effects on their Academic Success and Stress Management by Students-Case Study at Seinajoki University of Applied Sciences, Finland, 2017, Thesis, Faculty of Business Administration

[17] Cooper, C. L., \& Quick, J. C. (Eds.). The handbook of stress and health: A guide to research and practice. 2017, Hoboken, New Jersey, USA: John Wiley \& Sons.

[18] Taraj, P. The Relationship between Academic Stress of Students and the Factors that affect on it. The First International Conference on Research and Education-Challenges toward the Future (ICRAE, 2013), 24th- 25th May, 2013

[19] Ahmed, U., Riazand, A., \& Ramzan, M. Assessment of Stress and Stressors: A Study on Management Students. Interdisciplinary Journal of Contemporary Research in Business, 2013, 4(9): 687-699

[20] Zawawi, D. \& Jye, K. S. Understanding the stressors and coping strategies among MBA students in Malaysia, The 2012 International Conference on Business and Management 6 - 7 September 2012, Phuket - Thailand. Retrieved fromhttp://www.caalinteduorg.com/ibsm2012/ej ournal/022HRM-DhaliaZ\&KhoSJUnderstanding_The_Stre ssors_and.pdf

[21] Kiani, Z. S., Latif, R., Bibi, A., Rashid, S., \& Tariq, A. Effect of academic stress on the mental health among college and university students. MDSRC-2017 Proceedings, 27-28 December 2011, Pakistan

[22] Adiele, D., Chamisa, J. A., Morgan, G. P., Catherine, B. \& Carolyne, L. M. Association of Academic Stress, Anxiety and Depression with Social-Demographic among Medical Students. Int. Journal of Social Science Studies, 2018, Vol. 6, No. 6, pp. 27-32
[23] Ng, K. C., Chiu, W. K. \& Fong, B. Y. F. A Review of Academic Stress among Hong Kong Undergraduate Students. Journal of Modern Education Review, 2016, Vol. 6, No. 8, pp. 531-540

[24] Hashim, I. H. Cultural and Gender Differences in Perceptions of Stressors and Coping Skills: A Study of Western and African College Students in China. School Psychology International, 2003, 24, 182-203

[25] Chen, K. L. A Study of Stress Sources among College Students in Taiwan. Journal of Academic and Business Ethics, 2009, 2(14): 1-8

[26] Azila-Gbettor, E. M., Atatsi, E. A., Danku, L. S., Soglo, N. Y. Stress and Academic Achievement: Empirical Evidence of Business Students in a Ghanaian Polytechnic. International Journal of Research in Business Studies and Management, 2015, Vol. 2, Issue 4, pp. 78-98

[27] Stankovska, G., Dimitrovski, D., Angelkoska, S., Ibraimi, Z. \& Uka, V. Emotional Intelligence, Test Anxiety and Academic Stress among University Students. Education in Modern Society, BCES Conference Books, 2018, Vol. 16, pp. 157-164

[28] Zeidner, M. Sources of Academic Stress: The Case of First Year Jewish and Arab College Students in Israel. Higher Education, 1992, Vol. 24, No. 1, pp. 25-40

[29] Aam, M., Sara, S. S. \& Adamu, T. B. Coorelates of Workload and Academic Stress among Fresh Undergraduate Students at Abubakar Tafawa Balewa University, Bauchi-Nigeria. International Journal of Education and Evaluation, 2017, Vol. 3, No. 9, pp. 1-8

[30] Kadapatti, M. G. \& Vijayalaxmi, A.H.M. Stressors of Academic Stress-A Study of PreUniversity Students. Indian Journal of Science Resources, 2012, 3(1): 171-175

[31] Shkulaku R. Student's stress in higher education institutions: A critical review of foreign literatures and the ones in Albania. European Scientific Journal, August 2015, Special Edition), pp. 40-48.

[32] So, E. S. \& Park, B. M. Health behaviors and academic performance among Korean adolescents. Asian Nursing Research, 2016, Vol. 10, No. 2, pp. 123-127.

[33] Li, H. \& Lin, C. D. College Stress and Psychological Well-Being of Chinese College Students. Acta Psychological Sinica, 2003, 35(2), 222-230

[34] Ramli, N. H. H., Alavi, M., Mehrinezhad, S. A. \& Ahmadi, A. Academic Stress and Self-Regulation among University Students in Malaysia: Mediator Role of Mindfulness. Behav. Sci., 2018, 8, 12, 33-45

[35] Radcliff, C. \& Lester, H. Perceived Stress during Undergraduate Medical Training: A Qualitative Study. Medical Education, 2003, 37, 32-57

[36] Duncan-Williams, B. Academic Stress, Academic Performance and the Psychological Well-Being of Senior High School Remedial Students in the Greater Accra Region of Ghana. 2015, MPhil. Clinical Psychology, Legon: University of Ghana

[37] Teh, C. K., Ngo, C. W., Binti Zulkifli, R. A., Vellasamy, R. \& Suresh, K. Depression, anxiety and stress among undergraduate students: A cross-sectional study. Open 
Journal of Epidemiology, 2015, Vol. 5, No. 4, p. 260.

[38] Thawabieh, A. M., \& Qaisy, L. M. Assessing stress among university students. American International Journal of Contemporary Research, 2012, 2(2), 110-116.

[39] Pedersen D. E. \& Jodin V. Stressors associated with the School Spillover of College Undergraduate. The Social Science Journal, 2016, Vol. 1, No. 53, pp. 40-48

[40] Lin, Y. M. \& Chen, F. S. Academic Stress Inventory of Students at Universities and Colleges of Technology. World Transactions on Engineering and Technology Education, 2009, Vol. 7, No. 2, pp. 157-162

[41] Saipanish, R. Stress among Medical Students in a Thai Medical School. Medical Teacher, 2003, 25(5), 502-506

[42] Oginyi, R. C. N., Mbam, O. S., Sampson, N., Chukwudi, E. J. \& Nwoba, M. O. E. Personality Factors, Academic Stress and Socio-Economic Status as Factors in Suicide Ideation among Undergraduates of Ebonyi State University. Asian Social Science, 2018, Vol. 14, No. 9, pp. 25-37

[43] Busari, A. O. Evaluating the Relationship between Gender, Age, Depression and Academic Performance among Secondary School Students, International Journal of Interdisciplinary and Multidisciplinary Studies, 2012, 4(2), 6-12

[44] Ackon, P. K. Saving the sinking educational system in Ghana. January 2014, Retrieved from http://www.myjoyon line.com/opinion/. (Accessed 5/3/2019)

[45] Mulyadi, S., Rahardjo, W. \& Basuki A. H. The Role of Parent-Child Relationship, Self-Esteem, Academic Self-Efficacy to Academic Stress. Procedia-Social and Behavioral Sciences, 2016, Vol. 217, No. 603-608.

[46] Kumaran, S. \& Javid, J. A. Emotional Intelligence, Test Anxiety for Students. Indian Journal of Psychological Science, 2016, Vol. 6, No. 2, pp. 159-167

[47] Hanna, L., Wilson, M. \& Hanna, A. A Questionnaire Study to Investigate Stress among Future Pharmacists by Gender and Year Group. Pharmacy, 2018, 6, 75, 2-9

[48] Bataineh, M. Z. Academic stress among undergraduate students: the case of education faculty at King Saud University. International Interdisciplinary Journal of Education, 2013, 2(1), 82-88

[49] Alzahem, A.M., Van Der Molenand, H. T. \& De Boer, B. J. Effect of Year of Study on Stress Levels in Male Undergraduate Dental Students. Advances in Medical Education and Practice, 2013, 4: 217-222

[50] Saub, R., Rajesh, S. M., Muirhead, V., Dom T. M., Ismail, N. M., \& Jamaludin, M. Perception of dental stress and social support among Malaysian dental students. Annals of Dentistry (ADUM), 2013, 20(1), 1-7

[51] Continental Education Strategy for Africa (CESA 16-25), African Union Indicators Manual. www.adeanet.org (Accessed 2/2/2019)

[52] Cole, N. N., Nonterah, C. W., Utsey S. O., Hook J. N., Hubbard, R. R., Opare-Henaku, A. \& Fischer, N. L. Predictor and moderator effects of ego resilience and mindfulness on the relationship between academic stress and psychological well being in a sample of Ghanaian
College Students. Journal of Black Psychology, 2014, 1-18.

[53] Dhanalakshmi, K. \&Murty, K. V. S. N. Relationship between Study Habits and Academic Stress of B.Ed. Trainees. Scholarly Research Journal for Humanity Science and English Language, 2018, Vol. 6, pp. 7851-7856

[54] Creswell, J. W., \& Clark, V. L. P. Designing and conducting mixed methods research (2nd ed.). 2011, Thousand Oaks, CA: Sage Publications.

[55] Arozin, J. M., \& Cameron, R. The Application of mixed methods in organizational research: A literature review. Electronic Journal of Business Research Methods, 2010, 8(2), 95-105.

[56] Fraenkel, J., Wallen, N., \& Hyun, H. How to design and evaluate research in education (8th ed.). 2012, New York, NY: McGraw-Hill Companies.

[57] Moriarty, J. Qualitative Methods Overview (SSCR Methods Reviews). 2011, London: National Institute for Health Research School for Social Care

[58] Scott, D., \& Usher, R. Researching education: Data methods and theory in educational inquiry (2nd ed.). 2011, London: Continuum International Publishing Group.

[59] Nandamuri, P. \& Gowthami, C. Sources of Academic StressA Study on Management Students. Journal of Management and Science, Vol. 1, Issue 2, pp. 31-42

[60] Amanya, S. B., Nakitende, J. \& Ngabirano, T. D. A Cross-Sectional Study of Stress and Its Sources among Health Professional Students at Makerere University, Uganda. Wiley Online Library, 2018, Vol. 5, Issue 1, pp. 23-56

[61] Bedewy, D., \& Gabriel, A. Examining perceptions of academic stress and its sources among university students: The Perception of Academic Stress Scale. Health psychology open, 2015, 2(2), 23-41

[62] Vasquez, P. Religious coping and social support as mediators and/or moderators and acculturative stress in a latino community sample. December 2010, Retrieved from http://epublications.marquette.edu/theses_open/71(Accesse d 2/1/2019)

[63] Baldwin, D. A., Wilkinson, F. C. \& Barkley, D. C. Effective Management of Student Employment: Organizing for Standard Deployment in Academic Libraries. 2009, Englewood: Libraries Unlimited, Inc.

[64] Utsey, S. O., Adams, E. P., \& Bolden, M. Development and initial validation of the Africultural Coping Systems Inventory. Journal of Black Psychology, 2000, 26 (1), 194 215

[65] D' chunha, C. \& Shah, Z. Impact of Stress on Students Overall Performance in B-School. Int. Journal of Sci. Technol. Management, 2016, 5: 95-102

[66] Adom, D. Asante Cosmology and Nature Conservation at the Bomfobiri Wildlife Sanctuary. Nature Conservation Research, 2018, Vol. 3, No. 1, pp. 35-57

[67] Tartaro, J., Luecken, L. \& Gunn, H. E. Exploring Heart and Soul: Effects of Religiosity/Spirituality and Gender on Blood Pressure and Cortisol Stress Responses. Journal of Health Psychology, 2005, 10(6): 753-766 